- 研究报告・

\title{
地形对典型阔叶红松林灌木更新的影响
}

\author{
赵 雪 徐丽娜 金光泽* \\ (东北林业大学生态研究中心, 哈尔滨 150040)
}

\begin{abstract}
摘要: 依托黑龙江凉水国家级自然保护区9 ha典型阔叶红松林动态监测样地的 900 个 $2 \mathrm{~m} \times 2 \mathrm{~m}$ 样方, 对灌木 $(\mathrm{H} \geq$ $30 \mathrm{~cm}, \mathrm{DBH}<1 \mathrm{~cm}$ ) 进行了调查, 基于 2006 年、2008年和 2010 年3次调查数据, 分析了地形对灌木分布、死亡及新 增的影响。结果表明: 样地内共有灌木 18 种, 2006、2008和 2010 年的灌木总数分别为 18,253 株/ha、 27,383 株/ha和 23,300 株/ ha。地形对 10 种主要灌木的分布、死亡和新增均有显著的影响 $(P<0.05)$, 多数灌木种偏好坡中和山脊, 且 坡度 $>6^{\circ}$ 的地形; 坡向对大部分耐阴性较强的灌木的分布影响较小, 而喜光的毛榛子(Corylus mandshurica) 在阳坡和 半阳坡的密度显著高于其他坡向。刺五加(Acanthopanax senticosus)、东北山梅花(Philadelphus schrenkii)、光蓦溲疏 (Deutzia gladata)、黄花忍冬(Lonicera chrysantha)、瘤枝卫矛(Euonymus pauciflorus)、毛榛子和早花忍冬(Lonicera praeflorens)7种灌木 $\mathrm{DBH}<1 \mathrm{~cm}$ 的个体的分布、死亡和新增与其 $\mathrm{DBH} \geq 1 \mathrm{~cm}$ 的个体的分布表现基本一致。
\end{abstract}

关键词: 阔叶红松林, 地形, 死亡, 新增, 生态位分化

\section{Effect of topography on shrub regeneration in a mixed broadleaved-Korean pine forest in the Xiaoxing'an Mountains}

Xue Zhao, Lina Xu, Guangze Jin*

Center for Ecological Research, Northeast Forestry University, Harbin 150040

\begin{abstract}
To explore the response of shrubs to topographic heterogeneity, 900 perennial shrub (height $(\mathrm{H}) \geq$ $30 \mathrm{~cm}$, diameter at breast height $(\mathrm{DBH})<1 \mathrm{~cm})$ quadrats of $4 \mathrm{~m}^{2}(2 \mathrm{~m} \times 2 \mathrm{~m})$ were set up in a 9 ha plot in a typical mixed broadleaved-Korean pine forest in the Xiaoxing'an Mountains. All shrubs in the quadrats were tagged, measured for $\mathrm{H}$ and $\mathrm{DBH}$, and identified to the species level. Based on census data collected in 2006, 2008, and 2010, we found that a total of 18 shrub species existed in these quadrats. Approximately 18,253, 27,383 and 23,300 individuals per hectare were found in 2006, 2008, and 2010, respectively. Topography significantly affected the distribution, mortality and recruitment of the 10 major shrub species $(P<0.05)$. Most shrub species preferred terrain characterized by slope degree $>6^{\circ}$. Aspect had less effects on the distribution of most strong shade-tolerant shrub species, but the density of the shade-intolerant species Corylus mandshurica on sunny and semi-sunny slopes was significantly higher than other aspects. For Acanthopanax senticosus, Philadelphus schrenkii, Deutzia gladata, Lonicera chrysantha, Euonymus pauciflorus, Corylus mandshurica and Lonicera praeflorens, the distribution, mortality and recruitment of shrubs with DBH $<1$ $\mathrm{cm}$ were consistent with that of the shrubs with $\mathrm{DBH} \geq 1 \mathrm{~cm}$.
\end{abstract}

Key words: mixed broadleaved-Korean pine forest, topography, mortality, recruitment, niche separation

灌木作为森林群落中的一项重要组分, 其组成 结构及动态变化特征与环境因素密切相关, 是群落 生态学家一直关注的热点之一(Bruno et al., 2003; Holzapfel et al., 2006; Myers-Smith et al., 2011)。灌 木处于上层乔木树种的林冠下或林隙中, 其物种的
数量特征及空间分布格局等均会受到乔木树种的 制约和影响(Piao et al., 2013); 与此同时, 生境也可 直接或间接地制约灌木层种群的更新和演替(Jin et $a l ., 2007)$ 。在不同的时空尺度上，灌木物种的空间 分布取决于生物因子和环境因子的相互平衡

收稿日期: 2015-05-08; 接受日期: 2015-09-21

基金项目: 国家自然科学基金(31270473)和长江学者和创新团队发展计划(IRT_15R09)

* 通讯作者 Author for correspondence. E-mail: taxus@126.com 
(Coceur et al., 1997; Campagne et al., 2006)。

地形通过地貌过程影响土壤的水、热及养分的 再分配，进而对植被产生直接的空间再分配(Jin et al., 2002; 赵雪等, 2013)。地形作为生境因子的重要 组成部分, 其不均一性对灌木空间分布有明显的影 响(李新荣, 1997)。近年来, 森林灌木群落结构及空 间异质性方面的相关研究多有报道(刘妍妍等, 2014)。相关研究结果显示, 由不同生境引起的土壤 异质性会对灌木的分布产生显著影响 $(\mathrm{Su}$ et al., 2004; Hagos et al., 2005; Li et al., 2007; Li et al., 2008; Yang et al., 2011), 一些灌木物种具极强的可 塑性, 可通过改变自身形态和生理特征来适应环境 的变化(Zunzunegui et al., 2009)。然而这些研究大部 分缺乏对灌木种群年际变化的持续监测。

阔叶红松(Pinus koraiensis)林是我国东北东部 山区的地带性顶极植被, 是北温带生物多样性最高 的森林类型。近代以来, 由于人口的增长, 战争和 砍伐活动的频繁, 在我国较大面积保存的阔叶红松 林仅限于吉林省长白山地区和黑龙江省的完达山、 老爷岭、张广才岭和小兴安岭地区。监测灌木植被 在地形因子影响下的动态变化, 可为典型阔叶红松 林的更新动态研究提供基础数据。本文依托于黑龙 江凉水国家级自然保护区的9 ha阔叶红松林动态监 测样地，通过2006年、2008年、2010年的定位调查， 主要探讨: (1)灌木 $(H \geq 30 \mathrm{~cm}, \mathrm{DBH}<1 \mathrm{~cm})$ 的组成 和动态变化; (2)地形对灌木组成及分布的影响; (3) 地形对灌木的死亡及新增的影响。希望能为理解阔 叶红松林生物多样性的形成机制提供基础数据。

\section{1 研究方法}

\section{1 研究地区概况}

本研究地位于黑龙江省凉水国家级自然保护 区 $\left(47^{\circ} 10^{\prime} 50^{\prime \prime} \mathrm{N}, 128^{\circ} 53^{\prime} 20^{\prime \prime} \mathrm{E}\right)$ 。该地区属小兴安岭 南部达里带支脉的东坡, 低山丘陵地貌, 地带性土 壤为暗棕壤。本地区属大陆性夏雨季风气候, 春、 夏多西南风, 秋、冬多西北风。年平均气温 $-0.3^{\circ} \mathrm{C}$, 年均最高气温 $7.5^{\circ} \mathrm{C}$, 年均最低气温-6.6 ${ }^{\circ} \mathrm{C}$ 。海拔 280-707 m。本研究所选的样地位于保护区的中段, 从凉水沟谷地到海拔 $600 \mathrm{~m}$ 的中山山脊。地带性植 被是以红松为主的温带针阔叶混交林, 以红松为优 势种, 伴生的阔叶树种有青楷槭 (Acer tegmentosum)、水曲柳(Fraxinus mandshurica)、色木槭(Acer
mono)、紫椴(Tilia amurensis)、裂叶榆(Ulmus lacini$a t a)$ 等; 针叶树种有臭冷杉(Abies nephrolepis)、红皮 云杉(Picea koraiensis)、鱼鳞云杉(P. jezoensis)等; 灌 木有刺五加 (Acanthopanax senticosus)、毛榛子 (Corylus mandshurica)、东北山梅花(Philadelphus schrenkii)、光䒓溲疏(Deutzia gladata)等。

\section{2 灌木调查}

本研究依托于 9 ha的阔叶红松林永久性样地, 将样地设置成 900 个 $10 \mathrm{~m} \times 10 \mathrm{~m}$ 样方。于 2005 年7月, 以每个样方的西北角为原点, 在离原点 $1.5 \mathrm{~m}$ 处设 置 1 个平行于样方的 $2 \mathrm{~m} \times 2 \mathrm{~m}$ 的小样方。于 2006 年 调查小样方内灌木 (高度 $\geq 30 \mathrm{~cm}, \mathrm{DBH}<1 \mathrm{~cm}$ ), 记 录种名、高度和坐标, 悬挂有固定号码的铝牌, 于 2008年和2010年进行了2次复查。新增木是指调查 年新出现的符合要求的灌木, 死亡木是指上一次调 查出现而调查年没有再出现的灌木。对于成从的灌 木，不管其枝干在地下是否为同一个根系，若枝干 在地表表现为独立个体的均视为独立个体。

\section{3 地形调查}

将每个 $10 \mathrm{~m} \times 10 \mathrm{~m}$ 的样方划分成 4 个 $5 \mathrm{~m} \times 5 \mathrm{~m}$ 的小样方, 调查每个小样方的坡位、坡向、坡度。 其中坡位分为: 谷地、下坡、上坡和山脊; 坡向分 为: 阴坡 $\left(337.5^{\circ}-22.5^{\circ}, 22.5^{\circ}-67.5^{\circ}\right)$ 、半阴坡 $\left(67.5^{\circ}-\right.$ $\left.112.5^{\circ}, 292.5^{\circ}-337.5^{\circ}\right)$ 、平地、半阳坡 $\left(112.5^{\circ}-157.5^{\circ}\right.$, $\left.247.5^{\circ}-292.5^{\circ}\right)$ 和阳坡 $\left(157.5^{\circ}-247.5^{\circ}\right) 5$ 个等级; 坡度 分为: $<6^{\circ}, 6^{\circ}-15^{\circ}, 16^{\circ}-25^{\circ},>25^{\circ}$ 共 4 个等级(刘妍妍 等, 2009)。

\section{4 数据分析}

用标准的方法计算死亡率 $(m)$ 和新增率 $(r)$ :

$m=\left(\ln N_{0}-\ln S_{\mathrm{t}}\right) / T$

其中 $N_{0}$ 和 $N_{\mathrm{t}}$ 分别为在样地中第 1 次和第 2 次调查木本 植物的个体数, $S_{\mathrm{t}}$ 是第 2 次调查时仍存活的个体数, $T$ 为2次调查的时间间隔(Condit et al., 1999)。

利用卡方检验分析坡位、坡向及坡度等地形条 件对主要灌木的分布(2006年)、死亡木及新增木的 影响, $\mathrm{DBH} \geq 1 \mathrm{~cm}$ 的灌木的分布数据使用了 2010 年 的第一次复查数据(徐丽娜和金光泽, 2012)。

\section{2 结果}

\section{1 灌木组成与动态}

2006-2010年的3次调查中共记录到18个灌木 
种, 分属于7科 14 属。灌木种最多的科为忍冬科, 包 含 5 个种; 其次为虎耳草科和蓄微科。2006年、2008 年和 2010 年调查出现的灌木种数分别为 $17 、 18 、 18$ 个种, 个体数分别为 6,571 株 $(18,253$ 株/ha)、9,858株 (27,383株/ha)和8,388株(23,300株/ha)(表1)。

个体数 $\geq 100$ 株 $/ \mathrm{ha}$ 的灌木, 2006 年有 12 种, 分别 为刺五加、大叶小檗(Berberis poiretii)、东北茶蔍子 (Ribes mandshuricum)、东北山梅花、光墓溲疏、黄 花忍冬(Lonicera chrysantha)、瘤枝卫矛(Euon- ymus pauciflorus)、柳叶绣线菊(Spiraea salicifolia)、毛榛 子、暖木条荚蒾(Viburnum burejaeticum)、早花忍冬 (Lonicera praeflorens)、珍珠梅(Sorbaria sorbifolia), 其个体数之和占样地总灌木个体数的 $99.2 \%$; 而 2008年和2010年均有13种, 与2006年相比均新增了 1 个种卫矛 (Euonymus sacrosancta), 其个体数之和 均占同年样地总灌木个体数的 $99.3 \%$ 。2006、2008、 2010年灌木个体数最多的种均为光颌溲疏, 占同年 样地总灌木个体数的 $27.3 \%$ 、 $26.8 \%$ 和 $26.4 \%$ 。

2006-2008年、2008-2010年灌木死亡个体数和新增 个体数最多的种也为光蓦潰疏, 分别占同年样地总 灌木死亡个体数的 $23.9 \%$ 和 $26.4 \%$ 及同年样地总灌 木新增个体数的 $25.4 \%$ 和 $22.5 \%$ 。2006-2008年死亡 个体数和死亡率均较高的种为黄花忍冬和珍珠梅, 而2008-2010年为东北茶蔍子和卫矛; 2006-2008年
和2008-2010年新增率最高的种为卫矛。

\section{2 地形对灌木分布的影响}

刺五加、东北茶蔍、东北山梅花、光蔩溲疏、 黄花忍冬、瘤枝卫矛、柳叶绣线菊、毛榛子、早花 忍冬以及珍珠梅 10 个主要灌木的分布均与地形显 著相关 $(P<0.05$, 表 2$)$ 。坡位对10种灌木的分布均有 显著影响, 刺五加、光颌溲疏、毛榛子在斜坡(下坡 和上坡)和山脊，东北茶蔍在下坡和山脊，东北山梅 花和黄花忍冬在下坡, 瘤枝卫矛、早花忍冬在上坡 和山脊, 柳叶绣线菊在山脊, 珍珠梅在谷地和山脊 的分布显著高于其他坡位，其中刺五加、瘤枝卫矛 和早花忍冬 3 种灌木密度随着坡位的上升而增加， 在山脊密度最高。

9 种灌木在不同坡向的分布差异极显著 $(P<$ $0.001)$, 刺五加在阴坡、半阴坡、半阳坡和阳坡, 东 北茶蔍在半阴坡，东北山梅花在半阳坡和阳坡，光 䓵潰疏在半阴坡、半阳坡和阳坡，黄花忍冬在阴坡、 半阴坡和半阳坡, 瘤枝卫矛、早花忍冬在半阴坡和 阳坡，毛榛子在阴坡、半阴坡和阳坡，珍珠梅在平 地分布的数量均显著高于其他坡向。

坡度对 10 种灌木的分布影响显著, 刺五加、光 萝溲疏和毛榛子在 $\geq 6^{\circ}$, 东北茶蔍和东北山梅花在 $6^{\circ}-15^{\circ}$, 黄花忍冬在 $6^{\circ}-15^{\circ}$ 和 $>25^{\circ}$, 瘤枝卫矛、早花 忍冬在 $\geq 16^{\circ}$, 柳叶绣线菊在坡度 $<6^{\circ}$ 和 $\geq 16^{\circ}$, 珍珠梅

\section{表1 典型阔叶红松林灌木不同年份组成、死亡和新增数量及其死亡率和新增率(株/0.36 ha)}

Table 1 Mortality, recruitment, mortality rate and recruitment rate for shrub species in a mixed broadleaved-Korean pine forest in different years (inds./0.36 ha)

\begin{tabular}{|c|c|c|c|c|c|c|c|c|c|c|c|}
\hline \multirow[t]{2}{*}{ 物种 Species } & \multicolumn{3}{|c|}{$\begin{array}{c}\text { 个体数量 } \\
\text { No. of individuals }\end{array}$} & \multicolumn{2}{|c|}{$\begin{array}{c}\text { 死亡个体数 } \\
\text { No. of mortality }\end{array}$} & \multicolumn{2}{|c|}{$\begin{array}{l}\text { 新增个体数 } \\
\text { No. of } \\
\text { recruitments }\end{array}$} & \multicolumn{2}{|c|}{$\begin{array}{c}\text { 死亡率 } \\
\text { Mortality rate }\end{array}$} & \multicolumn{2}{|c|}{$\begin{array}{c}\text { 新增率 } \\
\text { Recruitment rate }\end{array}$} \\
\hline & 2006 & 2008 & 2010 & $\begin{array}{c}2006- \\
2008 \\
\end{array}$ & $\begin{array}{c}2008- \\
2010 \\
\end{array}$ & $\begin{array}{c}2006- \\
2008 \\
\end{array}$ & $\begin{array}{c}2008- \\
2010 \\
\end{array}$ & $\begin{array}{c}2006- \\
2008 \\
\end{array}$ & $\begin{array}{c}2006- \\
2008 \\
\end{array}$ & $\begin{array}{c}2006- \\
2008 \\
\end{array}$ & $\begin{array}{c}2008- \\
2010 \\
\end{array}$ \\
\hline 刺醋李 Ribes burejense & 3 & 13 & 13 & 1 & 2 & 11 & 2 & 0.203 & 0.084 & 0.936 & 0.084 \\
\hline 刺玫果 Rosa acicularis & 22 & 27 & 30 & 6 & 4 & 11 & 7 & 0.159 & 0.080 & 0.262 & 0.133 \\
\hline 刺五加 Acanthopanax senticosus & 928 & 1,528 & 1,190 & 135 & 476 & 735 & 138 & 0.079 & 0.187 & 0.328 & 0.062 \\
\hline 大叶小檗 Berberis poiretii & 62 & 109 & 95 & 11 & 26 & 58 & 12 & 0.098 & 0.136 & 0.380 & 0.068 \\
\hline 东北茶蔍子 Ribes mandshuricum & 237 & 453 & 349 & 43 & 151 & 259 & 47 & 0.100 & 0.203 & 0.424 & 0.072 \\
\hline 东北山梅花 Philadelphus schrenkii & 693 & 975 & 900 & 109 & 214 & 391 & 139 & 0.086 & 0.124 & 0.256 & 0.084 \\
\hline 光蓸潰疏 Deutzia gladata & 1,793 & 2,643 & 2,212 & 277 & 685 & 1,127 & 254 & 0.084 & 0.150 & 0.278 & 0.061 \\
\hline 黄花忍冬 Lonicera chrysantha & 837 & 1,038 & 912 & 188 & 265 & 389 & 139 & 0.127 & 0.147 & 0.235 & 0.083 \\
\hline 鸡树条荚蒾 Viburnum sargenti & 17 & 22 & 17 & 6 & 8 & 11 & 3 & 0.218 & 0.226 & 0.347 & 0.097 \\
\hline 接骨木 Sambucus williamsii & 2 & 1 & 1 & 1 & 0 & 0 & 0 & 0.347 & 0.000 & 0.000 & 0.000 \\
\hline 瘤枝卫矛 Euonymus pauciflorus & 602 & 734 & 686 & 61 & 112 & 193 & 64 & 0.053 & 0.083 & 0.153 & 0.049 \\
\hline 柳叶绣线菊 Spiraea salicifolia & 94 & 215 & 172 & 14 & 75 & 135 & 32 & 0.081 & 0.214 & 0.494 & 0.103 \\
\hline 毛榛子 Corylus mandshurica & 913 & 1,265 & 1,118 & 186 & 288 & 538 & 141 & 0.114 & 0.129 & 0.277 & 0.067 \\
\hline 暖木条荚蒾 Viburnum burejaeticum & 76 & 111 & 106 & 19 & 28 & 54 & 23 & 0.144 & 0.145 & 0.333 & 0.122 \\
\hline 卫矛 Euonymus sacrosancta & 9 & 384 & 311 & 2 & 146 & 377 & 73 & 0.126 & 0.239 & 2.002 & 0.134 \\
\hline 悬钩子 Rubus arcticus & 0 & 2 & 1 & 0 & 1 & 2 & 0 & 0.000 & 0.347 & 0.000 & 0.000 \\
\hline 早花忍冬 Lonicera praeflorens & 96 & 109 & 90 & 20 & 31 & 33 & 12 & 0.117 & 0.167 & 0.180 & 0.072 \\
\hline 珍珠梅 Sorbaria sorbifolia & 187 & 229 & 185 & 79 & 87 & 121 & 43 & 0.274 & 0.239 & 0.376 & 0.132 \\
\hline 总计 Total & 6,571 & 9,858 & 8,388 & 1,158 & 2,599 & 4,445 & 1,129 & 0.097 & 0.153 & 0.300 & 0.072 \\
\hline
\end{tabular}




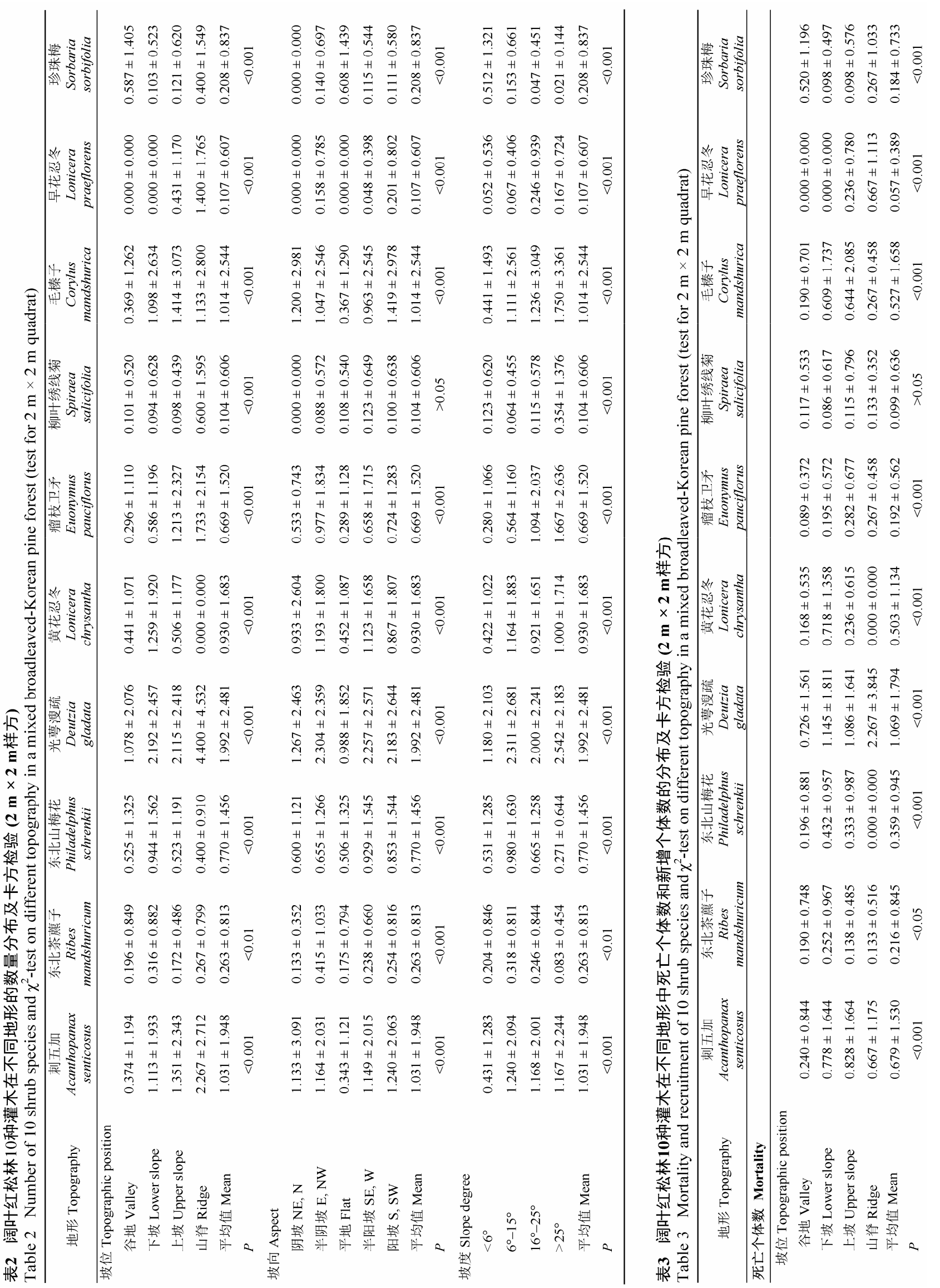




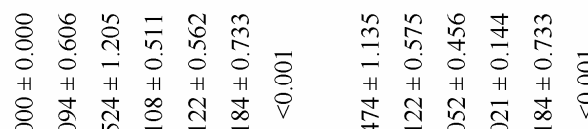

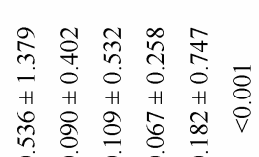

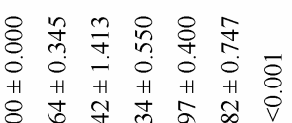

\&

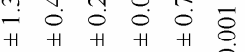

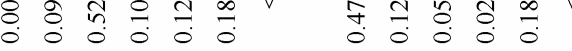

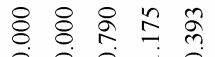

\& $\approx$ ते ते क्ष

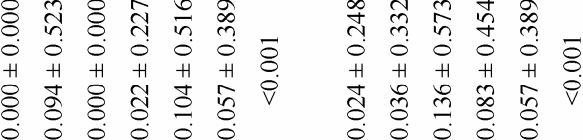

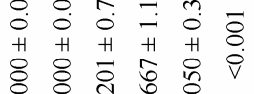

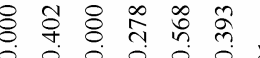

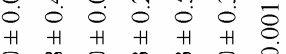

每

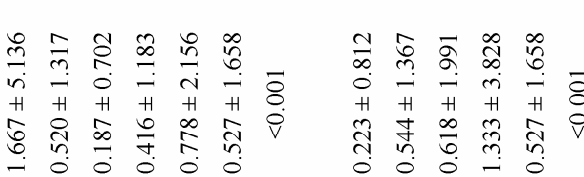

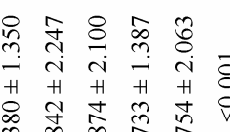

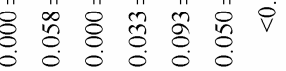

సิ 学导导 总

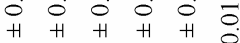

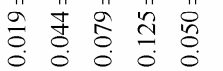

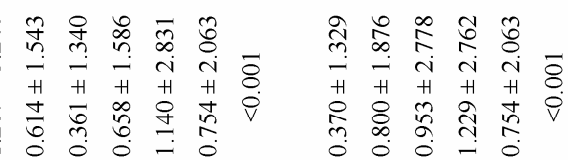

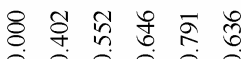

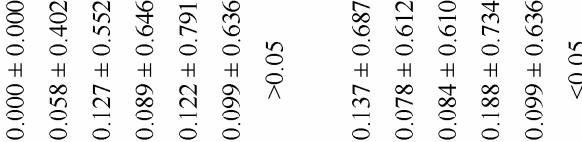

ర్ర0

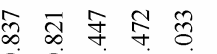

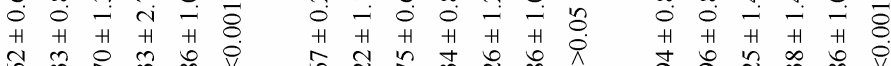

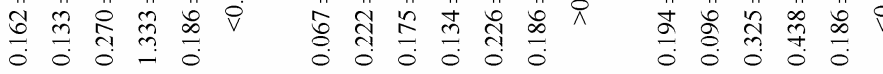

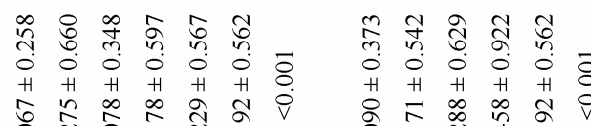

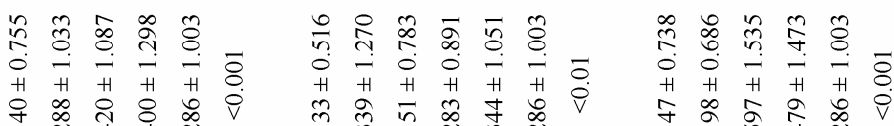

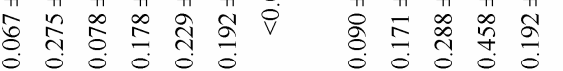

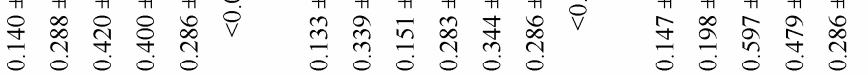

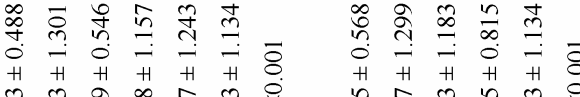

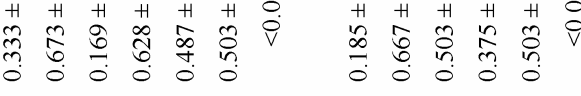

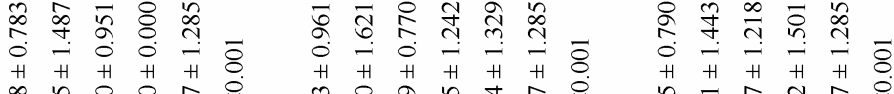

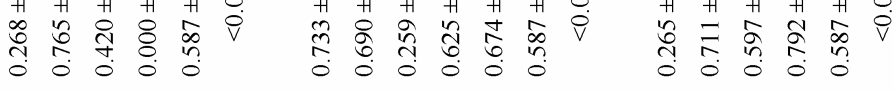

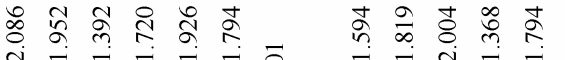

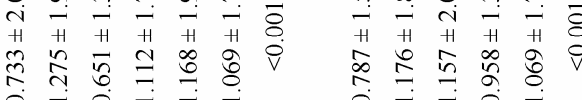

\& क

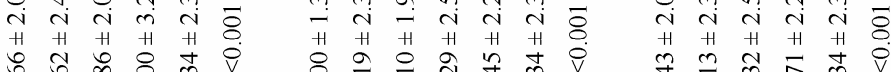

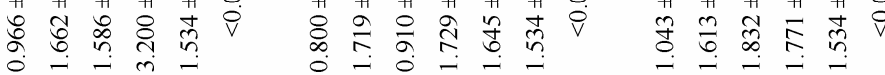

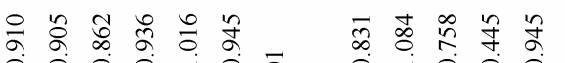

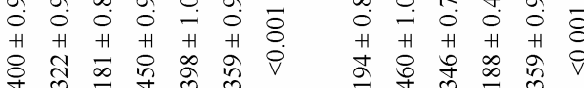

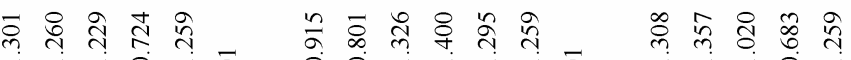

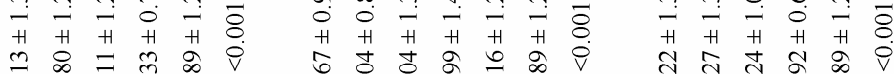

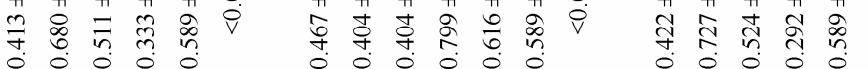

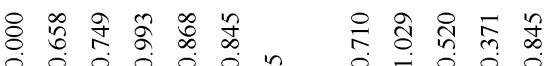

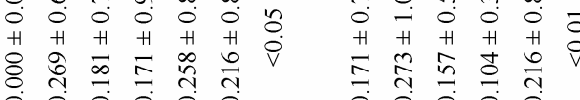

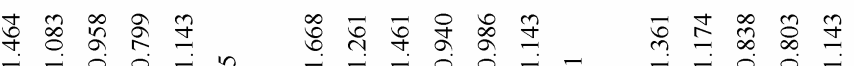

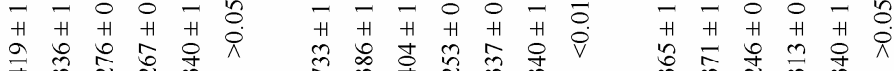

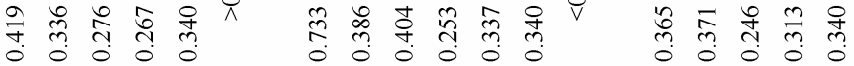

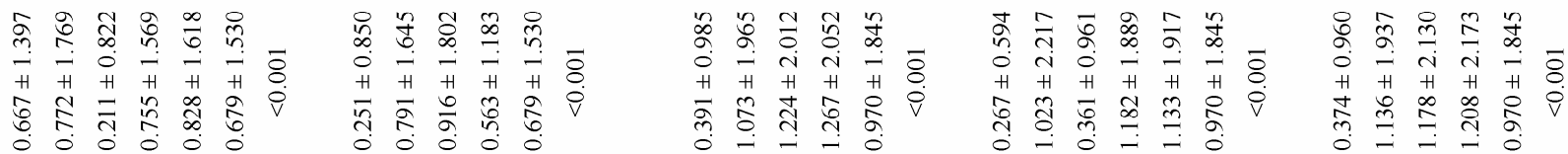

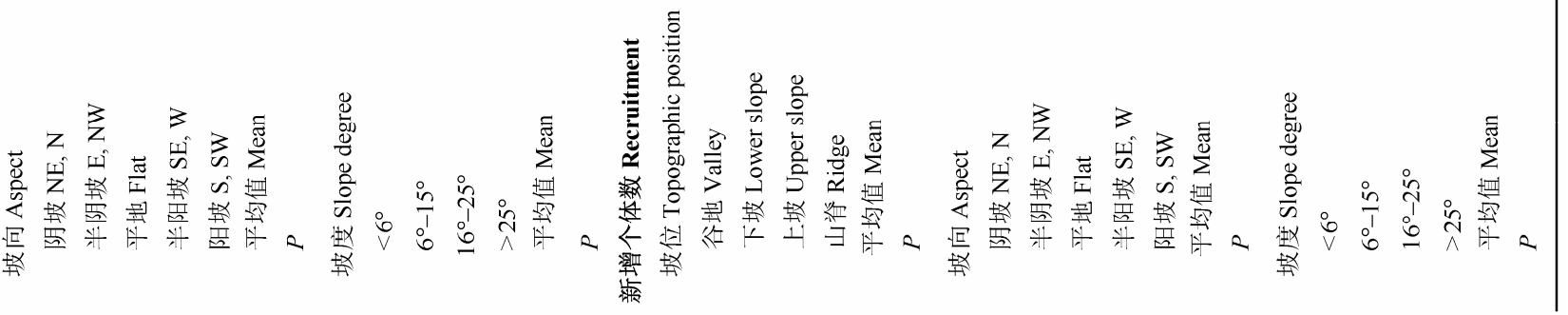


在 $<6^{\circ}$ 分布的数量均显著高于其他坡度, 其中瘤枝 卫矛和毛榛子的数量分布随着坡度变大而增多, 珍 珠梅的数量分布则随着坡度变大而减少。

\section{3 地形对灌木死亡的影响}

10 种灌木的死亡与地形均显著相关 $(P<0.05$, 表3)。坡位对9种灌木的死亡有显著影响, 刺五加和 毛榛子在斜坡，东北茶蔍、东北山梅花和黄花忍冬 在下坡, 光颌舅疏、瘤枝卫矛在斜坡和山脊, 早花 忍冬在上坡和山脊, 珍珠梅在谷地和山脊的死亡数 量显著高于其他坡位, 其中早花忍冬的死亡数量随 着坡位升高而增多。

坡向对9种灌木的死亡影响显著, 刺五加、光䓵 潰疏在半阴坡、半阳坡和阳坡，东北茶蔍、瘤枝卫 矛、早花忍冬在半阴坡和阳坡，东北山梅花在阴坡、 半阳坡和阳坡, 黄花忍冬在半阴坡和半阳坡, 毛榛 子在阴坡和阳坡, 珍珠梅在平地的死亡数量显著高 于其他坡向。

坡度对 10 种灌木死亡的影响显著, 刺五加和光 蓦舅疏在缓坡 $\left(6^{\circ}-15^{\circ}\right.$ 和 $\left.16^{\circ}-25^{\circ}\right)$, 东北茶蔍、东北山 梅花和黄花忍冬在 $6^{\circ}-15^{\circ}$, 瘤枝卫矛、早花忍冬在 $\geq 16^{\circ}$, 柳叶绣线菊在 $<6^{\circ}$ 和 $>25^{\circ}$, 毛榛子在 $\geq 6^{\circ}$, 珍珠 梅在 $<6^{\circ}$ 的死亡数量显著高于其他坡度, 其中瘤枝卫 矛和毛榛子的死亡表现出随着坡度变大而增多, 珍 珠梅则表现出随着坡度变大而减少的趋势。

\section{4 地形对灌木新增的影响}

10 种灌木的新增与地形显著相关 $(P<0.05$, 表 $3)$ 。坡位对9种灌木新增的影响极显著 $(P<0.001)$, 刺 五加、光颌溲疏、瘤枝卫矛在斜坡和山脊, 东北山 梅花和黄花忍冬在下坡, 柳叶绣线菊、早花忍冬在 上坡和山脊，毛榛子在上坡和下坡，珍珠梅在谷地 的新增数量显著高于其他坡位, 其中刺五加和早花 忍冬的新增数量随坡位上升而增多。

坡向对9种灌木的新增有显著影响, 刺五加、光 蔩溲疏在半阴坡、半阳坡和阳坡，东北茶蔍在阴坡、 半阴坡和平地, 东北山梅花在半阳坡和阳坡, 黄花 忍冬在阴坡、半阴坡、半阳坡和阳坡, 瘤枝卫矛、 早花忍冬在半阴坡和阳坡，毛榛子在阴坡和阳坡， 珍珠梅在平地的分布显著高于其他坡向。

坡度对9种灌木的新增有显著影响，刺五加、光 萝溲疏、黄花忍冬和毛榛子在 $\geq 6^{\circ}$, 东北山梅花在 $6^{\circ}-15^{\circ}$, 瘤枝卫矛、早花忍冬在 $\geq 16^{\circ}$, 柳叶绣线菊在 $<6^{\circ}$ 和 $\geq 16^{\circ}$, 珍珠梅在 $<6^{\circ}$ 处显著高于其他坡度, 其
中刺五加、毛榛子和早花忍冬的新增数量随着坡度 的变大而变大, 珍珠梅则随着坡度变大而减少。

\section{3 讨论}

\section{1 灌木组成}

黑龙江凉水 9 ha典型阔叶红松林动态监测样地 中共有 16 种灌木 (DBH $\geq 1 \mathrm{~cm}$ 且不含小乔木) (徐丽 娜等, 2012), 而2006-2010年3次调查中共出现18种 灌木 $(\mathrm{DBH}<1 \mathrm{~cm})$ 。其中, 蒿柳(Salix viminalis) 和谷 柳(S. starkeana var. livida) 的DBH $<1 \mathrm{~cm}$ 的个体没 有在小样方内出现, 刺醋李(Ribes burejense)、悬钩 子(Rubus arcticus)、柳叶绣线菊和卫矛的DBH $\geq 1$ $\mathrm{cm}$ 个体没有在样地中出现。由于所处阔叶红松林的 亚区不同, 凉水典型阔叶红松林样地与长白山阔叶 红松林样地在灌木组成上既存在较多共有物种 $(12$ 种, 除忍冬属), 又存在较大的差异。在凉水样地出 现而长白山样地没有出现的灌木有 4 种，分别为刺 醋李、悬钩子、刺玫果(Rosa acicularis)、光蓦溲疏; 而在长白山原始阔叶红松林出现但凉水没有出现 的有石蚕叶绣线菊(Spiraea chamaedryfolia)、东北舅 疏(Deutzia amurensis)、簇毛棫(Acer barbinerve)、翅 卫矛(Euonymus macropterus) 和刺蓄薇 (Rosa davurica) 5 种灌木(白雪娇等, 2010)。由此可见，气候的 差异使得红松伴生灌木的组成也有明显差异。

\section{2 地形对灌木分布、死亡和新增的影响}

坡位、坡向和坡度对 9 种主要灌木的分布均有 显著影响，且大部分灌木表现出分布多的地形中其 死亡率和新增率也高。刺五加、东北山梅花、光荳 溲疏、黄花忍冬、瘤枝卫矛、毛榛子和早花忍冬的 分布与其 $\mathrm{DBH} \geq 1 \mathrm{~cm}$ 的个体分布基本一致，而东北 茶蔍DBH $\geq 1 \mathrm{~cm}$ 的个体只受坡向的影响显著, 并和 $\mathrm{DBH}<1 \mathrm{~cm}$ 的个体分布有一致性, 3 个地形因子对 珍珠梅DBH $\geq 1 \mathrm{~cm}$ 的个体分布均无显著影响(表4)。 刺五加、东北山梅花、光颌溲疏、黄花忍冬、瘤枝 卫矛、毛榛子和早花忍冬 7 种灌木 $\mathrm{DBH}<1 \mathrm{~cm}$ 的个体 在不同地形下死亡数量和新增数量的分布与其 $\mathrm{DBH} \geq 1 \mathrm{~cm}$ 的个体分布一致。

地形作为间接因子对光、温度、水分和养分等 生态因子进行再分配, 进而显著地影响主要组成物 种的空间分布。坡位的上升影响着土壤含水量, 从 谷地到山脊，水分逐渐变少。主要灌木在斜坡和山 脊的分布均较多，尤其山脊处最多，说明灌木分布 
表4 不同地形中阔叶红松林主要灌木 $(\mathrm{DBH} \geqslant 1 \mathrm{~cm})$ 的数量分布及DBH $<1 \mathrm{~cm}$ 个体的分布、死亡和新增的卡方检验

Table 4 Distribution of major shrubs (DBH $\geqslant 1 \mathrm{~cm})$, and the distribution, mortality and recruitment of individuals $(\mathrm{DBH}<1 \mathrm{~cm})$ and $\chi^{2}$-test on different topography in a mixed broadleaved-Korean pine forest

\begin{tabular}{|c|c|c|c|c|c|c|c|c|c|c|c|c|c|c|}
\hline \multirow[b]{2}{*}{$\begin{array}{l}\text { 物种 } \\
\text { Species }\end{array}$} & \multirow[b]{2}{*}{$\begin{array}{l}\text { DBH } \\
(\mathrm{cm})\end{array}$} & \multicolumn{4}{|c|}{ 坡位 Topographic position } & \multicolumn{5}{|c|}{ 坡向 Aspect } & \multicolumn{4}{|c|}{ 坡度 Gradient } \\
\hline & & $\begin{array}{l}\text { 谷地 } \\
\text { Valley }\end{array}$ & $\begin{array}{c}\text { 下坡 } \\
\text { Lower slope }\end{array}$ & $\begin{array}{c}\text { 上坡 } \\
\text { Upper slope }\end{array}$ & $\begin{array}{c}\text { 山脊 } \\
\text { Ridge }\end{array}$ & $\begin{array}{l}\text { 阴坡 } \\
\mathrm{NE}, \mathrm{N}\end{array}$ & $\begin{array}{l}\text { 半阴坡 } \\
\mathrm{E}, \mathrm{NW}\end{array}$ & $\begin{array}{l}\text { 平地 } \\
\text { Flat }\end{array}$ & $\begin{array}{c}\text { 半阳坡 } \\
\mathrm{SE}, \mathrm{W}\end{array}$ & $\begin{array}{c}\text { 阳坡 } \\
\text { S, SW }\end{array}$ & $<6^{\circ}$ & $6^{\circ}-15^{\circ}$ & $16^{\circ}-25^{\circ}$ & $>25^{\circ}$ \\
\hline 刺五加 & $<1$ & & $* \star \star \lambda$ & $* \star \hbar \hat{\zeta}$ & *玄 & $*$ & 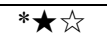 & & $* \star \star \hbar$ & $* \star \hbar \hat{\langle}$ & & $* \star \star \hbar$ & $* \star \hbar$ & $* \hat{厶}$ \\
\hline Acanthopanax senticosus & $\geq 1$ & & $*$ & $*$ & & & $*$ & & * & * & & $*$ & $*$ & \\
\hline 东北茶蔍子 & $<1$ & & $* \star$ & & * & 幽 & $* \star \star \tau$ & 绉 & & $\star$ & & $* \star$ & & \\
\hline Ribes mandshuricum & $\geq 1$ & & & & & $*$ & $*$ & & & & & & & \\
\hline 东北山梅花 & $<1$ & & $* \star$ 元 & & & $\star$ & & & $* \star \star s$ & $* \star \star 々 \gamma$ & & $* \star \hbar$ & & \\
\hline Philadelphus schrenkii & $\geq 1$ & & $*$ & & & & $*$ & & $*$ & & & $*$ & & \\
\hline 光蕓溲疏 & $<1$ & & 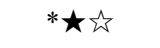 & $* \star \star 々$ & 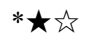 & & $* \star \hbar$ & & $* \star \star 々$ & $* \star \star s$ & & $* \star \star 々$ & $* \star \star 々 \gamma$ & $* \hbar$ \\
\hline Deutzia gladata & $\geq 1$ & & $*$ & * & & & $*$ & & $*$ & & & $*$ & $*$ & $*$ \\
\hline 黄花忍冬 & $<1$ & & $* \star \hbar$ & & & $* \hbar$ & $* \star \hbar$ & & $* \star \star s$ & $\hbar$ & & $* \star \star 々$ & 论 & $* \hbar$ \\
\hline Lonicera chrysantha & $\geq 1$ & & $*$ & $*$ & $*$ & & $*$ & & $*$ & $*$ & & $*$ & $*$ & $*$ \\
\hline 瘤枝卫矛 & $<1$ & & $\star$ 分 & $* \star \star 々$ & 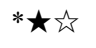 & & $* \star \hbar$ & & & $* \star \star 々 \zeta$ & & & $* \star \lesssim$ & $* \star \star \Delta$ \\
\hline Euonymus pauciflorus & $\geq 1$ & & $*$ & $*$ & $*$ & $*$ & $*$ & & $*$ & $*$ & & & $*$ & $*$ \\
\hline 柳叶绣线菊 & $<1$ & & & $\sum$ & $* \hbar$ & & & & & & $* \star \hbar$ & & $* \hbar$ & $* \star \star \Delta$ \\
\hline Spiraea salicifolia & $\geq 1$ & & & & & & & & & & & & & \\
\hline 毛榛子 & $<1$ & & $* \star \star 认$ & $* \star \star 力$ & * & $* \star \star \tau$ & $*$ & & & $* \star \star \tau$ & & $* \star \star 々$ & $* \star \hbar$ & $* \star \star \Delta$ \\
\hline Corylus mandshurica & $\geq 1$ & & $*$ & $*$ & * & & & & * & * & & $*$ & $*$ & $*$ \\
\hline 早花忍冬 & $<1$ & & & $* \star \star \gamma$ & 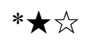 & & $* \star \hbar$ & & & $* \star \star 力 r$ & & & $* \star \star 々$ & $* \star \star \Delta$ \\
\hline Lonicera praeflorens & $\geq 1$ & & & $*$ & $*$ & $*$ & $*$ & & $*$ & * & & & $*$ & $*$ \\
\hline 珍珠梅 & $<1$ & 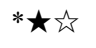 & & & $* \star$ & & & $* \star$ 放 & & & $* \star$ 它 & & & \\
\hline Sorbaria sorbifolia & $\geq 1$ & & & & & & & & & & & & & \\
\hline
\end{tabular}

* 分布 Distribution; $\star$ 死亡 Mortality; 新增 Recruitment

广, 耐干旱。坡向的变化影响着光照、温度和水分 (Hutchinson et al., 1999; 刘妍妍和金光泽, 2009), 从阴坡到阳坡, 光照愈来愈充足, 温度相应地升高, 水分却愈来愈少。由于灌木上层有乔木分布, 坡向 对刺五加、光萼溲疏、早花忍冬、黄花忍冬、东北 山梅花等大部分耐阴性较强的灌木的分布影响较 小, 只有较耐阴的东北茶蔍其阴坡和半阴坡的密度 显著高于其他坡向; 而喜光的毛榛子其阳坡、半阳 坡的密度显著高于其他坡向。珍珠梅属阳性物种, 但由于喜湿润土壤, 因此主要分布在平地。瘤枝卫 矛和柳叶绣线菊均喜光, 稍耐庇荫, 其中瘤枝卫矛 喜湿润山坡, 因此平地的分布显著低于山坡, 柳叶 绣线菊喜湿润土壤，因此坡向对其分布没有显著影 响。坡度的变化影响着土壤的厚度和含水量 (Tokuchi et al., 1999), 缓坡处土层较厚, 水分充足; 陡坡处土层较薄, 水分比较少(沈泽昊等, 2000)。主 要灌木多分布在有坡之处, 说明灌木喜排水良好的 土壤, 对稳定土壤具有重要意义。

灌木更新受光照、土壤温湿度、动物活动等直 接因子以及伴生乔木的分布、地形等间接因子的影
响。本文着重分析了地形对典型阔叶红松林灌木的 分布、死亡和新增的影响, 而有关灌木更新的其他 生物因子和非生物因子的影响有待于长期监测和 进一步研究。

\section{参考文献}

Bai XJ (白雪娇), Li BH (李步航), Zhang J (张健), Wang LW (王利伟), Yuan ZQ (原作强), Lin F (萄菲), Hao ZQ (郝占 庆) (2010) Species composition, structure, and spatial distribution of shrubs in broad-leaved Korean pine (Pinus koraiensis) mixed forest in Changbai Mountains. Chinese Journal of Applied Ecology (应用生态学报), 21, 1899-1906. (in Chinese with English abstract)

Bruno JF, Stachowicz JJ, Bertness MD (2003) Inclusion of facilitation into ecological theory. Trends in Ecology and Evolution, 18, 119-125.

Campagne P, Roche P, Tatoni T (2006) Factors explaining shrub species distribution in hedgerows of a mountain landscape. Agriculture, Ecosystems and Environment, 116, 244-250.

Coeur DL, Baudry J, Burel F (1997) Field margins plant assemblages: variation partitioning between local and landscape factors. Landscape Urban Planning, 37, 57-71.

Condit R, Ashton PS, Manokaran N, LaFrankie JV, Hubbell SP, Foster RB (1999) Dynamics of the forest communities at 
Pasoh and Barro Colorado: comparing two 50-ha plots. Philosophical Transactions of the Royal Society of London Series B: Biological Sciences, 354, 1739-1748.

Hagos MG, Smit GN (2005) Soil enrichment by Acacia mellifera subsp. detinens on nutrient poor sandy soil in a semi-arid southern African savanna. Journal of Arid Environments, 61, 47-59.

Holzapfel C, Tielbörger K, Parag HA, Kigel J, Sternberg M (2006) Annual plant-shrub interactions along an aridity gradient. Basic and Applied Ecology, 7, 268-279.

Hutchinson TF, Boerner REJ, Iverson LR, Sutherland S, Sutherland EK (1999) Landscape patterns of understory composition and richness across a moisture and nitrogen mineralization gradient in Ohio (U.S.A.) Quercus forests. Plant Ecology, 144, 177-189.

Jin GZ, Tang Y, Kim JH (2002) The interpretation of community structure for the natural deciduous forest of Mt. Chumbong classified by TWINSPAN. Journal of Korean Forestry Society, 91, 523-534.

Jin GZ, Tian YY, Zhao FX, Kim JH (2007) The pattern of natural regeneration by gap size in the broadleaved-Korean pine mixed forest of Xiaoxing'an Mountains, China. Journal of Korean Forest Society, 96, 227-234.

Li J, Zhao C, Zhu H, Li Y, Wang F (2007) Effect of plant species on shrub fertile island at an oasis-desert ecotone in the South Junggar Basin, China. Journal of Arid Environments, 71, 350-361.

Li PX, Wang N, He WM, Krüsi BO, Gao SQ, Zhang SM, Yu FH, Dong M (2008) Fertile islands under Artemisia ordosica in inland dunes of northern China: effects of habits and plant developmental stages. Journal of Arid Environments, 72, 953-963.

Li XR (李新荣) (1997) Analyzing construction of shrub layer in different communites in the spruce-broadleaved mixed geobotanical zone of Moscow state. Chinese Bulletin of Botany (植物学通报), 14, 40-48. (in Chinese with English abstract)

Liu YY (刘妍妍), Jin GZ (金光泽) (2009) Influence of topography on coarse woody debris in a mixed broadleavedKorean pine forest in Xiaoxing'an Mountains, China. Acta Ecologica Sinica (生态学报), 29, 1398-1407. (in Chinese with English abstract)

Liu YY (刘妍妍), Jin GZ (金光泽), Li FR (李凤日) (2014) Influence of forest gaps on seedling establishment in a mixed broadleaved-Korean pine (Pinus koraiensis) forest in Xiao Hinggan Mountains. Chinese Science Bulletin (科学通 报), 59, 2396-2406. (in Chinese with English abstract)
Myers-Smith IH, Forbes BC, Wilmking M, Hallinger M, Lantz T, Blok D, Tape KD, Macias-Fauria M, Sass-Klaassen U, L'evesque E, Boudreau S, Ropars P, Hermanutz L, Trant A, Collier LS, Weijers S, Rozema J, Rayback SA, Schmidt NM, Schaepman-Strub G, Wipf S, Rixen C, M'enard CB, Venn S, Goetz S, Andreu-Hayles L, Elmendorf S, Ravolainen V, Welker J, Grogan P, Epstein HE, Hik DS (2011) Shrub expansion in tundra ecosystems: dynamics, impacts and research priorities. Environmental Research Letter, 6, 045509.

Piao TF, Comita LS, Jin GZ, Kim JH (2013) Density dependence across multiple life stages in a temperate old-growth forest of northeast China. Oecologia, 172, 207-217.

Shen ZH (沈泽吴), Zhang XS (张新时), Jin YX (金义兴) (2000) Gradient analysis of the influence of mountain topography on vegetation pattern. Acta Phytoecologica Sinica (植物生态学报), 24, 430-435. (in Chinese with English abstract)

Su YZ, Zhao HL, Zhang TH, Li YL (2004) Characteristics of plant community and soil properties in the plantation chronosequence of Caragana microphylla in Horqin sandy land. Acta Phytoecologica Sinica (植物生态学报), 28, 93-100.

Tokuchi N, Takeda H, Yoshida K, Iwatsubo G (1999) Topographical variations in a plant-soil system along a slope on $\mathrm{Mt}$ Ryuoh, Japan. Ecological Research, 14, 361-369.

Xu LN (徐丽娜), Jin GZ (金光泽) (2012) Species composition and community structure of a typical mixed broadleaved-Korean pine (Pinus koraiensis) forest plot in Liangshui Nature Reserve, Northeast China. Biodiversity Science (生物多样性), 20, 470-481. (in Chinese with English abstract)

Yang ZP, Zhang Q, Wang YL, Zhang JJ, Chen MC (2011) Spatial and temporal variability of soil properties under Caragana microphylla shrubs in the northwestern Shanxi Loess Plateau, China. Journal of Arid Environments, 75, $538-544$.

Zhao X (赵雪), Liu YY (刘妍妍), Jin GZ (金光泽) (2013) Effects of topography on seedling regeneration in a mixed broadleaved-Korean pine forest in Xiaoxing'an Mountains, Northeast China. Chinese Journal of Applied Ecology (应用 生态学报), 24, 3035-3042. (in Chinese with English abstract)

Zunzunegui M, Ain-Lhout F, Díaz Barradas MC, ÁlvarezCansino L, Esquivias MP, García Novo F (2009) Physiological, morphological and allocation plasticity of a semi-deciduous shrub. Acta Oecologica, 35, 370-379. 